\title{
an examination of a cumulus cloud width-height measure under the efiects of seeding'
}

\begin{abstract}
A width-height measure of cloud shape is used to investigate possible effects of seeding summer cumulus clouds with silver iodide. Evidence is presented to show that seeding may cause decreases in the width-height ratios of cloud echoes and that these effects may extend beyond the region of silver iodide transport.
\end{abstract}

\section{Introduction}

Evidence for the possibility that seeding with silver iodide causes growth of cumulus clouds, hence differing width-height ratios for cloud radar echoes, has come to light during the analysis of Project Whitetop data. Malkus and Simpson (1964) in a study of tropical clouds have shown that seeding has an effect on vertical cumulus cloud growth. In the present study radar echoes taken from Project Whitetop data have been used to establish a quantitative description of cloud formation which has proven to be useful in a study of the effects of seeding.

Project Whitetop was a study of the effects of seeding summertime non-orographic, convective clouds. It was carried out during June, July and August, 1960 through 1964, near West Plains, Mo. Two methods of assessing the effects of the seeding were used; a network of recording rain gages and a ground-based range height indicator radar.

A possible natural division of the experimental days based upon radar recorded, cumulus cloud echo-profiles was observed. Two categories were seen: one had a typically uniform, low, broad cloud structure; the other had a typically tall, thin cloud structure. Since all radar films had been coded with a set of preselected, randomly generated numbers concealing calendar date, this observation was made without knowing when seeding had occurred. Nevertheless it was hypothesized that these categories represented seeded and not-seeded days, respectively. As a test of this hypothesis, the project statistician chose 18 days to be qualitatively identified as seeded or as not seeded. Of this sample 14 days were judged correctly, 2 days were judged incorrectly, and

1 Research supported under NSF Grant GA-851.

21968 winner of the AMS Father James B. Macelwane Award. judgment was reserved on 2 days because of lack of cloud cover.These results suggested that cloud shape might be related to the seeding effect. This paper is a report of a preliminary examination of this problem.

\section{Sources of data}

The details of Project Whitetop have been reported by Braham (1966). For the present study the essential points concerning Project Whitetop are as follows:

The project operated on all days which satisfied preselected regional meteorological parameters suggesting conditions favorable for cloud growth. On these "operational" days the decision to seed, or not seed was made according to a pre-determined, randomly generated set of instructions.

Seeding was performed for 6 continuous hours along a 30-mile seeding line on the upwind side of the research area. The silver iodide was released at or just below the height of the cloud bases, and was envisaged to flow downwind, mixing both horizontally and vertically in what was called the plume area. The plume area was defined ${ }^{3}$ as "that area downwind of the seeding line which was encompassed laterally by the most divergent wind directions between the seeding level and 14,000 $\mathrm{ft}$, and encompassed fore and aft by the extreme wind displacements, at any level, for every direction." Thus the silver iodide should have been entirely contained in the plume area at all times. However, this does not imply that all of the plume area was seeded, nor does it imply that all seeding effects were limited to the plume area. Unknown larger scale effects could have occurred. (A larger scale effect has been suggested as an explanation for other results of Project Whitetop, Braham (1965).) The plume was computed for each hour on the basis of data from pilot balloons released every other hour, and on the basis of Circuit $\mathrm{C}$ upper wind data.

The hours of seeding were chosen so as to give the largest plume areas during the normal period of maximum frequency of afternoon convective cloudiness. The main source of data for the present study was an AN/TPS-10 height-finder radar with a 3-cm wavelength and a range of just over 60 miles. It was located about 11 miles east of West Plains, Missouri at $36^{\circ} 45.0^{\prime} \mathrm{N}$ and

3 Braham (1966), page 21. 
$91^{\circ} 39.4^{\prime} \mathrm{W}$. On all operational days the radar was run from 1 hour after the beginning of the seeding period (or the same time on not-seeded days) through the late evening hours. It was operated in a continuous azimuthal scan at 360 degrees per 3 minutes. Therefore each sweep covered a 2-degree azimuthal segment of the clouds in the research area, from ground level to an altitude of $60 \mathrm{~K}$. One hundred eighty such sweeps thus gave a picture of all of the clouds in the research area. Analysis of radar data was restricted to the interval 10-60 miles because the radar could not see the tops of the clouds at close range.

\section{Test for differences between seeded and not-seeded days}

A width-height measurement of radar echoes is a convenient and easily measurable approximation to the vertical cloud shape. Therefore it easily lends itself to testing for seeding effect. The technique developed for such measurements is illustrated in Fig. 1 and Table 1. For a particular azimuthal sweep of the radar, $k$, let $D_{i j}$ be the coordinate at which echo is found, where $i$ is the range from the radar in miles and $j$ is the predetermined height in multiples of $10,000 \mathrm{ft}$. Then $\sum_{i j} D_{i j}$ is the total number of miles of echo measured within the domain of $i$ and at heights $j$. Using $\sum_{i j} D_{i j}$ we find an expression for a mean width to height ratio for the echoes in the sweep:

$$
T_{k}=\frac{\sum_{i j} D_{i j}}{h_{k} \sum_{j} I_{j}}
$$

where $T_{k}$ is the width-height measure for the particular sweep, $k, I_{j}$ is the number of discrete echoes at height $j$, and $h_{k}$ is the height of the tallest echo in the sweep in tens of thousands of feet, rounded down to the nearest 10,000 feet.

These parameters were easily accessible from existing data recorded from Project Whitetop radar films. These data included an indication of the presence (yes-no) of echoes for every 1 mile range (10-60 miles), for every 2 degrees of azimuth (full $360^{\circ}$ scan), for every 10,000 foot height interval, once each hour.

The analyses in this study were performed on a sample chosen from these data. Then days, 5 seeded and 5 notseeded, were selected from each of the years 1960, 1962 and 1964. In order to minimize possible seasonal effects the days were selected on a basis of calendar date so as to spread them out over each of the summers. Days with less than 5 hours of cloud echoes were eliminated before the sample for this study was chosen. This was done because days with little cloud cover were assumed not to have given the seeding particles an adequate chance to produce any effects. Also, during 1960 some difficulties with the silver iodide burners were encountered, and those days having less than one-half of the optimum number of burner hours were eliminated before the choice of the sample.

For each hour of the 30 days thus selected, 4 randomly chosen sweeps containing cloud echoes were observed. The width-height measures of each of these sweeps, $T_{k}$, were computed and from them a mean hourly value, $T$ was obtained.

TABLE 1. Calculation of the width-height measure $T_{k}$ from Fig. 1.

\begin{tabular}{c|r|r}
\hline \hline Height & $\sum_{i} D_{i j}$ & $I_{i}$ \\
\cline { 2 - 3 } $10 \mathrm{~K}$ & 8 & 1 \\
$20 \mathrm{~K}$ & 11 & 2 \\
$30 \mathrm{~K}$ & 10 & 1 \\
$40 \mathrm{~K}$ & 9 & 1 \\
$50 \mathrm{~K}$ & 4 & 1 \\
$60 \mathrm{~K}$ & 0 & 0 \\
\hline
\end{tabular}



Fig. 1. Sample sweep, seeded day.

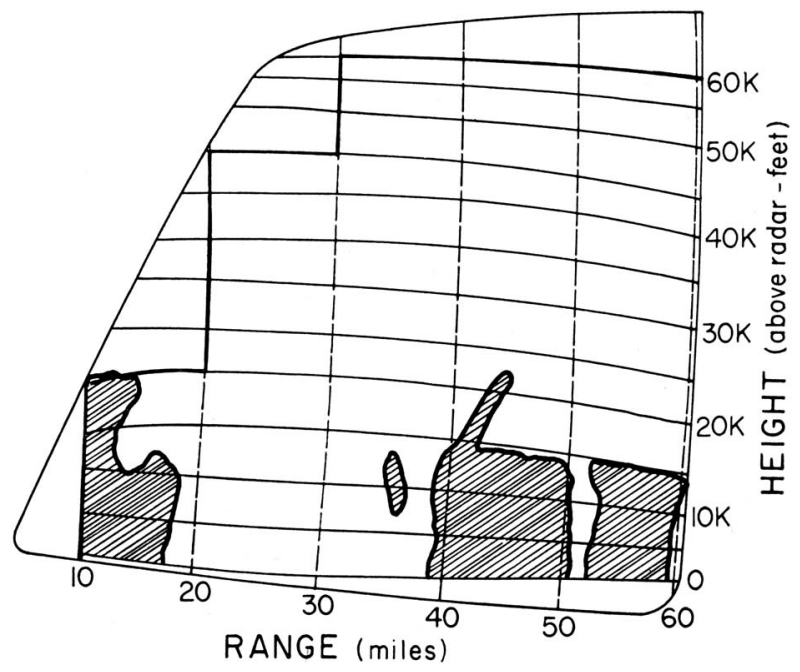

Fic. 2. Sample sweep, not-seeded day. 
An example of the calculation of $T_{k}$ can be seen in Table 1 and Fig. 1. Daily values of $T$ were calculated

$$
\begin{aligned}
\sum_{i j} D_{i j} & =42 \\
\sum_{i} I_{j} & =6 \\
h & =5 \\
T_{k} & =\frac{\sum_{i j} D_{i j}}{h_{k} \sum_{j} I^{j}}=\frac{42}{5(6)}=1.40
\end{aligned}
$$

from the hourly values for that day. The mean for seeded days was $\bar{T}_{s}=1.16 \pm 0.44$ and the mean for notseeded days was $\bar{T}_{n s}=2.30 \pm 1.36$, where the errors shown are the standard deviations of the daily values of $T$. Sample seeded and not-seeded sweeps are illustrated in Figs. 1 and 2. The values of $T$ for all hours of all days are given in Tables 2 and 3. An illustration of the distribution of the daily values of $T$ their means, and their standard deviations are indicated in Fig. 3.

These data were tested using a " $t$ " test ${ }^{4}$ and because of the extreme non-normality of most precipitation data, a non-parametric test, the Wilcoxon 2-sample rank test, ${ }^{5}$

\footnotetext{
${ }_{4}$ Brownlee (1955), p. 297

5 Brownlee (1965), p. 51.
}



FIG. 3. Distribution of values of the width-height measure, $T$, for seeded and not-seeded days, their means and standard deviations.

was also used. Both tests give probabilities of 0.001 of getting such a difference between seeded and not-seeded days by chance. This strongly suggests that the distribution of width-height measure, $T$, is different on seeded and not-seeded days. Values of $T_{k}$ were computed for all sweeps containing echoes on 18 of the 30 days. These all-sweep values were used in comparison with the foursweep data to determine the sampling error introduced by the use of only four sweeps. The all-sweep values are in parentheses in Tables 2 and 3 below the four-sweep data. Using all-sweep data the seeded and not-seeded

\begin{tabular}{|c|c|c|c|c|c|c|c|c|c|c|c|c|c|}
\hline \multirow{2}{*}{ Day } & \multicolumn{11}{|c|}{ Hour-CST } & \multicolumn{2}{|c|}{ Daily mean values } \\
\hline & 1100 & 1200 & 1200 & 1400 & 1500 & 1600 & 1700 & 1800 & 1900 & 2000 & 2100 & 4-sweep & All-sweep \\
\hline 139 & - & $\begin{array}{c}1.90 \\
(2.35)\end{array}$ & $\begin{array}{c}1.00 \\
(1.64)\end{array}$ & $\begin{array}{l}0 \\
0\end{array}$ & $\begin{array}{l}0 \\
0\end{array}$ & $\begin{array}{l}0 \\
0\end{array}$ & $\begin{array}{c}1.00 \\
(1.33)\end{array}$ & $\begin{array}{c}1.75 \\
(1.30)\end{array}$ & $\begin{array}{c}1.25 \\
(1.29)\end{array}$ & $\begin{array}{l}0 \\
0\end{array}$ & $\begin{array}{c}1.88 \\
(1.41)\end{array}$ & 0.89 & 0.93 \\
\hline 101 & - & $\begin{array}{c}1.21 \\
(2.03)\end{array}$ & $\begin{array}{c}2.53 \\
(1.97)\end{array}$ & $\begin{array}{c}2.79 \\
(1.72)\end{array}$ & $\begin{array}{c}1.38 \\
(1.73)\end{array}$ & $\begin{array}{c}1.63 \\
(1.57)\end{array}$ & $\begin{array}{c}1.75 \\
(1.86)\end{array}$ & $\begin{array}{c}1.83 \\
(1.64)\end{array}$ & $\begin{array}{c}2.38 \\
(1.62)\end{array}$ & $\begin{array}{c}2.19 \\
(1.50)\end{array}$ & $\begin{array}{l}0 \\
0\end{array}$ & 1.77 & 1.56 \\
\hline 166 & - & $\begin{array}{c}1.00 \\
(2.87)\end{array}$ & - & - & $\begin{array}{c}1.50 \\
(1.57)\end{array}$ & $\begin{array}{c}2.00 \\
(2.00)\end{array}$ & $\begin{array}{l}0 \\
0\end{array}$ & $\begin{array}{l}0 \\
0\end{array}$ & $\begin{array}{c}1.29 \\
(1.73)\end{array}$ & $\begin{array}{c}2.63 \\
(3.33)\end{array}$ & $\begin{array}{c}1.00 \\
(1.00)\end{array}$ & 1.18 & 1.56 \\
\hline 162 & 一 & $\begin{array}{c}1.35 \\
(0.99)\end{array}$ & $\begin{array}{c}1.16 \\
(1.85)\end{array}$ & $\begin{array}{c}2.36 \\
(2.21)\end{array}$ & $\begin{array}{c}0.88 \\
(1.74)\end{array}$ & $\begin{array}{c}1.35 \\
(2.23)\end{array}$ & $\begin{array}{c}2.73 \\
(2.57)\end{array}$ & $\begin{array}{c}3.60 \\
(3.36)\end{array}$ & $\begin{array}{c}3.08 \\
(2.32)\end{array}$ & $\begin{array}{c}0.61 \\
(0.82)\end{array}$ & $\begin{array}{c}0.65 \\
(1.77)\end{array}$ & 1.78 & 1.99 \\
\hline 189 & - & $\begin{array}{c}1.25 \\
(1.46)\end{array}$ & $\begin{array}{c}2.25 \\
(2.07)\end{array}$ & $\begin{array}{c}1.50 \\
(1.60)\end{array}$ & $\begin{array}{l}0 \\
0\end{array}$ & $\begin{array}{c}2.33 \\
(2.33)\end{array}$ & $\begin{array}{c}1.50 \\
(1.50)\end{array}$ & $\begin{array}{c}2.50 \\
(2.30)\end{array}$ & $\begin{array}{c}3.50 \\
(3.50)\end{array}$ & $\begin{array}{c}3.00 \\
(2.40)\end{array}$ & $\begin{array}{c}1.25 \\
(1.33)\end{array}$ & 1.91 & 1.85 \\
\hline 396 & $\begin{array}{c}2.33 \\
(2.33)\end{array}$ & $\begin{array}{c}1.43 \\
(1.55)\end{array}$ & $\begin{array}{c}2.00 \\
(1.53)\end{array}$ & $\begin{array}{c}1.96 \\
(1.65)\end{array}$ & $\begin{array}{c}1.86 \\
(2.00)\end{array}$ & $\begin{array}{c}3.92 \\
(2.93)\end{array}$ & $\begin{array}{c}1.50 \\
(1.50)\end{array}$ & $\begin{array}{l}0 \\
0\end{array}$ & $\begin{array}{l}0 \\
0\end{array}$ & $\begin{array}{l}0 \\
0\end{array}$ & $\begin{array}{l}0 \\
0\end{array}$ & 1.36 & 1.23 \\
\hline 348 & - & - & - & $\begin{array}{l}0 \\
0\end{array}$ & $\begin{array}{c}0.94 \\
(1.29)\end{array}$ & $\begin{array}{c}1.19 \\
(1.68)\end{array}$ & $\begin{array}{c}1.25 \\
(1.58)\end{array}$ & $\begin{array}{c}1.73 \\
(1.34)\end{array}$ & $\begin{array}{c}1.00 \\
(1.00)\end{array}$ & $\begin{array}{l}0 \\
0\end{array}$ & $\begin{array}{l}0 \\
0\end{array}$ & 0.76 & 0.86 \\
\hline 392 & $\begin{array}{c}1.50 \\
(1.72)\end{array}$ & $\begin{array}{c}1.25 \\
(1.25)\end{array}$ & $\begin{array}{c}1.00 \\
(1.00)\end{array}$ & $\begin{array}{c}1.00 \\
(1.00)\end{array}$ & $\begin{array}{l}0 \\
0\end{array}$ & $\begin{array}{l}0 \\
0\end{array}$ & $\begin{array}{l}0 \\
0\end{array}$ & $\begin{array}{l}0 \\
0\end{array}$ & $\begin{array}{c}0.74 \\
(0.63)\end{array}$ & $\begin{array}{c}2.18 \\
(1.98)\end{array}$ & $\begin{array}{c}1.40 \\
(1.14)\end{array}$ & 0.82 & 0.79 \\
\hline 399 & - & $\begin{array}{c}1.25 \\
(1.25)\end{array}$ & $\begin{array}{c}1.25 \\
(1.25)\end{array}$ & $\begin{array}{c}2.50 \\
(2.13)\end{array}$ & $\begin{array}{c}2.50 \\
(2.08)\end{array}$ & $\begin{array}{c}2.50 \\
(2.50)\end{array}$ & $\begin{array}{l}0 \\
0\end{array}$ & $\begin{array}{l}0 \\
0\end{array}$ & $\begin{array}{l}0 \\
0\end{array}$ & $\begin{array}{l}0 \\
0\end{array}$ & $\begin{array}{l}0 \\
0\end{array}$ & 1.00 & 0.92 \\
\hline 390 & $\begin{array}{l}0 \\
0\end{array}$ & $\begin{array}{l}0 \\
0\end{array}$ & $\begin{array}{l}0 \\
0\end{array}$ & $\begin{array}{c}0.83 \\
(0.90)\end{array}$ & $\begin{array}{c}1.00 \\
(0.83)\end{array}$ & $\begin{array}{c}1.35 \\
(1.11)\end{array}$ & $\begin{array}{c}0.63 \\
(0.98)\end{array}$ & $\begin{array}{c}2.40 \\
(1.60)\end{array}$ & $\begin{array}{c}1.25 \\
(0.70)\end{array}$ & $\begin{array}{l}0 \\
0\end{array}$ & - & 0.75 & 0.61 \\
\hline 590 & 0 & 0 & 0 & 0 & 0 & 0 & 1.14 & 1.47 & 2.69 & 2.10 & 1.48 & 0.81 & \\
\hline 353 & 一 & 1.75 & 1.38 & - & 1.27 & 2.00 & 2.39 & 1.81 & 0 & 0 & 0 & 1.18 & \\
\hline 547 & 0 & 0.79 & 0.88 & 2.44 & 0.88 & 1.44 & 1.80 & 0 & 0 & 0 & 0 & 0.75 & \\
\hline 552 & 0 & 1.31 & 0.69 & 0.96 & 1.83 & 2.11 & 21.6 & 3.65 & 2.06 & 1.13 & 3.13 & 1.73 & \\
\hline 506 & - & 1.38 & 1.52 & 2.81 & 0 & 1.29 & 0 & 0 & 0 & 0 & 0 & 0.70 & \\
\hline $\begin{array}{c}\text { Mean 4- } \\
\text { sweep } \\
\text { data }\end{array}$ & 0.64 & 1.22 & 1.26 & 1.49 & 0.94 & 1.54 & 1.19 & 1.39 & 1.28 & 0.92 & 0.74 & 1.16 & 1.23 \\
\hline
\end{tabular}
means for $T$ were $T_{s}=1.23 \pm .48$ and $T_{n s}=2.03 \pm 1.62$.

TABLE 2. Values of the width-height measure, $\mathrm{T}$, for seeded days. All-sweep data are in parentheses below four-sweep data. 
A " $t$ " test on these values gave a probability of .076 of getting such a difference or a greater one by chance alone.

The distribution of the mean hourly values of $T$ for seeded and not-seeded days are shown in Tables 2 and 3. We see that the echo shape differs most markedly towards the ends of the days. This result is surprising in terms of a simple seeding hypothesis since the maximum difference between seeded and not-seeded days occurs after the end of seeding. Statistical results of rainfall data from Project Whitetop also suggest a maximum seeding effect in the late hours of the day. ${ }^{6}$

\section{Width-height comparisons inside and outside the plume area}

If the difference in echo shape which has been observed between seeded and not-seeded days is attributed to seeding one would expect the effect to be most prominent in the plume area on seeded days. This assumes that the seeding effects are confined to the area of wind transport of the seeding agent. One would expect to see the absence of such effects in the non-plume area on seeded days and in both areas on not-seeded days. Therefore, the values of $T$ are compared for the following 4 categories:

6 Private communication with the Project Whitetop statistician, J. Flueck.
1) plume area, seeded days

2) non-plume area, seeded days

3) plume area, not-seeded days

4) non-plume area, not-seeded days.

One would expect that sample 1 above might have significantly different values of $T$ from the other 3 categories and that these other categories would be similar to each other.

It was found that only $11.3 \%$ of the sweeps, taken from the four-sweep data, had echo in both the plume and the non-plume. For the remaining $88.7 \%$ of the sweeps it was possible to assign the sweep to either the plume or non-plume areas. For these cases values of $T$ were calculated for each of the categories as shown in Table 4.

The values of $T$ in the 4 categories were pooled and tested using a non-parametric test, the " $H$ " test, 7 was used to see if they could be considered as belonging to a single group. The statistic from this " $H$ " test was 671.01 with 3 degrees of freedom. This can be compared to the value 6.25 obtained from a Chi-square table at a $90 \%$ significant level with 3 degrees of freedom. Thus it appears that the 4 categories are nonhomogeneous, as

7 Brownlee (1965), p. 256.

TABLE 3. Values of the width-height measure, $\mathrm{T}$, for not-seeded days. All-sweep data are in parentheses below four-sweep data.

\begin{tabular}{|c|c|c|c|c|c|c|c|c|c|c|c|c|c|}
\hline \multirow{2}{*}{ Day } & \multicolumn{11}{|c|}{ Hour-CST } & \multicolumn{2}{|c|}{ Daily mean valuee } \\
\hline & 1100 & 1200 & 1300 & 1400 & 1500 & 1600 & 1700 & 1800 & 1900 & 2000 & 2100 & 4-sweep & All-sweep \\
\hline \multirow[t]{2}{*}{190} & - & - & 1.69 & 1.69 & 1.02 & 1.18 & 2.78 & 1.63 & 1.28 & - & 0 & 1.41 & \\
\hline & - & - & $(1.49)$ & $(1.66)$ & $(1.78)$ & (1.48) & (1.75) & $(1.83)$ & $(1.76)$ & - & 0 & & 1.47 \\
\hline \multirow[t]{2}{*}{192} & - & 1.75 & 2.17 & 3.58 & 2.75 & 1.25 & 1.75 & 2.50 & 2.50 & 2.83 & 4.08 & 2.52 & \\
\hline & 一 & (2.11) & $(2.12)$ & $(2.66)$ & $(2.42)$ & $(1.73)$ & (1.19) & $(2.50)$ & $(2.13)$ & $(3.87)$ & $(3.88)$ & & 2.45 \\
\hline \multirow[t]{2}{*}{168} & - & 3.04 & 1.79 & 2.09 & 6.75 & 3.27 & 5.29 & 2.44 & 3.07 & 4.42 & 2.75 & 3.49 & \\
\hline & - & $(2.36)$ & $(3.09)$ & $(4.50)$ & $(5.44)$ & $(3.91)$ & $(4.59)$ & $(2.51)$ & $(4.07)$ & $(4.35)$ & $(2.05)$ & & 3.69 \\
\hline \multirow[t]{2}{*}{153} & - & 0 & 1.00 & 1.00 & 1.00 & 1.25 & 1.13 & 0 & 0 & 0 & 0 & 0.54 & \\
\hline & - & 0 & $(1.00)$ & $(1.00)$ & $(1.00)$ & $(1.21)$ & $(1.27)$ & 0 & 0 & 0 & 0 & & 0.55 \\
\hline \multirow[t]{2}{*}{125} & - & - & - & 2.25 & 1.00 & 1.00 & 0.70 & 0.65 & 1.38 & 1.25 & 0 & 1.03 & \\
\hline & - & - & - & $(2.03)$ & $(1.00)$ & $(1.00)$ & $(0.92)$ & $(1.22)$ & $(1.12)$ & $(1.17)$ & 0 & & 1.06 \\
\hline \multirow[t]{2}{*}{327} & 1.54 & 2.25 & 1.00 & 1.38 & 2.28 & 0 & 2.20 & 1.89 & 3.00 & 2.36 & 2.79 & 1.88 & \\
\hline & $(1.84)$ & (1.88) & $(1.00)$ & $(1.27)$ & $(2.13)$ & 0 & $(2.12)$ & $(3.32)$ & $(2.74)$ & $(3.50)$ & $(3.67)$ & & 2.13 \\
\hline \multirow[t]{2}{*}{342} & 3.23 & 2.54 & 7.83 & 5.80 & 5.33 & 6.75 & 0 & 91.00 & 3.25 & 10.08 & 3.81 & 6.15 & \\
\hline & $(3.44)$ & $(4.26)$ & $(5.96)$ & $(4.90)$ & $(6.13)$ & $(6.47)$ & 0 & (12.83) & $(2.75)$ & $(4.40)$ & $(6.50)$ & & 5.24 \\
\hline \multirow[t]{2}{*}{344} & 0 & 0 & 0 & 0 & 1.58 & 1.85 & 2.22 & 2.65 & 1.63 & 1.92 & 9.25 & 1.92 & \\
\hline & 0 & 0 & 0 & 0 & $(1.49)$ & (1.95) & $(2.63)$ & $(2.42)$ & $(1.82)$ & $(3.23)$ & $(4.98)$ & & 1.68 \\
\hline 306 & 3.11 & 14.80 & 4.56 & 2.37 & 3.35 & 2.54 & 1.83 & 1.86 & 3.04 & 2.13 & 1.38 & 3.73 & \\
\hline 341 & 0 & 0 & 0 & 2.18 & 5.13 & 1.07 & 2.50 & 1.95 & 3.17 & 6.06 & 4.00 & 2.37 & \\
\hline 583 & 0 & 1.50 & 2.22 & 2.75 & 1.73 & 1.52 & 1.28 & 1.00 & 1.18 & 3.00 & 0 & 1.35 & \\
\hline 572 & 1.33 & 2.63 & 2.28 & 2.19 & 2.55 & 3.55 & 0 & 0 & 0 & 2.50 & 1.44 & 1.70 & \\
\hline 585 & 1.59 & 1.69 & 5.57 & 2.99 & 4.08 & 1.73 & 2.47 & 1.90 & 1.88 & 0 & 0 & 2.08 & \\
\hline 582 & 1.44 & 1.08 & 0.83 & 1.31 & 0.80 & 1.43 & 4.32 & 4.51 & 5.57 & 4.78 & 1.89 & 2.54 & \\
\hline 537 & - & 3.14 & 2.40 & 4.42 & 2.18 & 0.63 & 0 & 0 & 0 & 1.50 & 3.13 & 1.74 & \\
\hline \multirow{2}{*}{$\begin{array}{c}\text { Mean 4- } \\
\text { sweep } \\
\text { data }\end{array}$} & & & & & & & & & & & & & \\
\hline & 1.33 & 2.51 & 2.33 & 2.40 & 2.50 & 1.93 & 1.89 & 2.79 & 2.06 & 3.00 & 2.63 & 2.30 & 2.03 \\
\hline
\end{tabular}


TABLE 4. Daily values of the height-width measure, T, for plume and non-plume areas on seeded and not-seeded days. (Four-sweep data.)

\begin{tabular}{c|c|c|c|c|c}
\hline \multirow{2}{*}{ Day } & \multicolumn{2}{|c|}{ Seeded days } & & \multicolumn{2}{c|}{ Not-seeded days } \\
\cline { 2 - 3 } \cline { 5 - 6 } & $\begin{array}{c}\text { Plume } \\
\text { area }\end{array}$ & $\begin{array}{c}\text { Non-plume } \\
\text { area }\end{array}$ & Day & $\begin{array}{c}\text { Plume } \\
\text { area }\end{array}$ & $\begin{array}{c}\text { Non-plume } \\
\text { area }\end{array}$ \\
139 & 1.11 & 1.74 & 190 & 1.61 & 1.45 \\
101 & 2.13 & 1.82 & 192 & 1.93 & 0 \\
166 & 1.50 & 1.54 & 168 & 3.17 & 3.18 \\
162 & 1.72 & 1.16 & 153 & 1.11 & 3.10 \\
189 & 2.00 & 2.11 & 125 & 1.33 & 1.00 \\
396 & 2.87 & 1.92 & 327 & 2.68 & 1.78 \\
348 & 1.25 & 1.27 & 342 & 2.84 & 2.56 \\
392 & 1.33 & 1.38 & 344 & 2.45 & 2.73 \\
399 & 3.00 & 1.72 & 306 & 1.67 & 11.18 \\
390 & 0 & 1.22 & 341 & 5.82 & 2.23 \\
590 & 2.05 & 1.88 & 583 & 1.46 & 9.20 \\
535 & 1.92 & 1.65 & 572 & 0 & 2.05 \\
547 & 1.11 & 1.74 & 585 & 1.89 & 2.22 \\
552 & 2.79 & 1.52 & 583 & 3.25 & 2.85 \\
506 & 1.37 & 2.68 & 537 & 2.39 & 1.18 \\
\hline Mean & 1.74 & 1.69 & & 2.24 & 2.83 \\
Std. dev. & $(0.76)$ & $(0.37)$ & & $(1.01)$ & $(1.46)$ \\
\hline
\end{tabular}

would be expected from the analysis of Section 3. The same test was run on categories 2, 3 and 4 to see if they could be considered to be homogeneous. For this test the " $H$ " statistic was 18.55 for 2 degrees of freedom. This compares to a Chi-square statistic of 4.61 . Thus it also appears that the non-plume area on seeded days cannot be considered as being homogeneous with the plume and non-plume areas on not-seeded days.

From an examination of Table 4, and the results obtained above, it appears that the plume and non-plume areas exhibit the same echo shape characteristics as measured by $T$ on seeded and on not-seeded days, and that the differences observed in part 3 lie between seeded and not-seeded days and not within the days.

\section{Discussion}

This work leads to two conclusions:

a) The distribution in $T$ is markedly different on seeded than on not-seeded days. The $p$ values for getting the observed or greater differences merely by chance were .001 for the four-sweep analysis of 30 days and .076 for the all-sweep analysis of 18 of the 30 days. In my opinion, these are encouraging results and suggest the need for further study along these lines.

b) The effects of seeding in modifying the echo shape factor, $T$, extend beyond the plume area to such an extent that the plume area cannot be considered as significantly different from the non-plume area. As an explanation for other analysis of Project Whitetop, Braham (1965) has suggested a possible seeding effect extending outside of the plume area which does not depend directly upon interaction with seeding particulates. The existence of such effects bear further consideration.

Acknowledgments. The study was performed under the guidance of Profs. Bernice Ackerman and Roscoe R. Braham of the Department of Geophysical Sciences at the University of Chicago. Their guidance and encouragement was deeply appreciated. I am indebted to the Cloud Physics Laboratory staff as a whole, particularly to Dr. John Flueck for his statistical assistance and continued interest in this paper; to Miss M. Dungey for her help in locating data; and to Mr. R. Polomski for his assistance with the drawings.

\section{References}

Braham, R. R., Jr., 1965: Project Whitetop-A five year randomized cloud seeding study. Paper given at American Meteorological Society Conference on Cloud Physics and Severe Storms, Reno, Nevada.

-, 1966: Final report-Project Whitetop, Parts I and II. University of Chicago, Chicago, Ill. $156 \mathrm{pp}$.

Brownlee, K. A., 1965: Statistical Theory and Methodology in Science and Engineering. John Wiley \& Sons, Inc. New York, N. Y., 590 pp.

Malkus, J. S., and R. H. Simpson, 1964: Modification experiments on tropical cumulus clouds. Science, 145, 541-548. 